\title{
Discovering the key genes and important DNA methylation regions in breast cancer
}

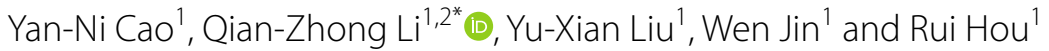

\begin{abstract}
Background: Breast cancer is the malignant tumor with the highest incidence in women. DNA methylation has an important effect on breast cancer, but the effect of abnormal DNA methylation on gene expression in breast cancer is still unclear. Therefore, it is very important to find therapeutic targets related to DNA methylation.

Results: In this work, we calculated the DNA methylation distribution and gene expression level in cancer and paracancerous tissues for breast cancer samples. We found that DNA methylation in key regions is closely related to gene expression by analyzing the relationship between the distribution characteristics of DNA methylation in different regions and the change of gene expression level. Finally, the 18 key genes (17 tumor suppressor genes and 1 oncogene) related to prognosis were confirmed by the survival analysis of clinical data. Some important DNA methylation regions in these genes that result in breast cancer were found.
\end{abstract}

Conclusions: We believe that 17 TSGs and 1 oncogene may be breast cancer biomarkers regulated by DNA methylation in key regions. These results will help to explore DNA methylation biomarkers as potential therapeutic targets for breast cancer.

Keywords: Breast cancer, DNA methylation, Oncogene, Tumor suppressor gene, Biomarker

\section{Background}

Breast cancer is the most commonly diagnosed cancer. Worldwide, breast cancer is the leading type of cancer in women, there were about 2.26 million newly diagnosed female breast cancer cases and about 0.68 million death in 2020 [1]. The mortality rate of breast cancer has been decreased compared with the past, which is attributed to the early diagnosis of breast cancer and the improvement of the level for surgery, radiotherapy, and chemotherapy [2-5]. In addition, new targeted drug therapies have significantly improved the survival of breast cancer patients. However, the target drugs for breast cancer are relatively

\footnotetext{
*Correspondence: qzli@imu.edu.cn

${ }^{1}$ Laboratory of Theoretical Biophysics, School of Physical Science

and Technology, Inner Mongolia University, No.235 West Daxue Street,

Saihan District, Hohhot 010021, P.R. China

Full list of author information is available at the end of the article
}

lacking $[6,7]$. Therefore, it is important to find new target genes related to the pathogenesis of breast cancer.

Epigenetics is a heritable variation that can cause changes in gene expression [8]. DNA methylation is considered a biomarker for epigenome analysis $[9,10]$. Many studies have reported that DNA methylation can affect gene expression, which is an important factor in the development and progression of cancer [11]. Wholegenome hypomethylation and gene-specific hypermethylation were associated with malignant tumors $[9,12]$. In particular, hypermethylation of tumor suppressor genes (TSGs) can lead to cancer development [13-15]. For example, CAV1 [16], CDH13 [17], ID4 [18], and SCGB3A1 [19] are epigenetically regulated by DNA hypermethylation in breast carcinogenesis. The hypermethylation in promoters of APC, SFRP1, SFRP2, SFRP5, WIF1, DKK3, ITIH5, and RASSF1A [17] are associated with the development of breast cancer, and studies have found that $A P C$ and RASSF $1 A$ are common epigenetic 
biomarkers for early detection of breast cancer [20-22]. Experiments have demonstrated that abnormal DNA methylation in the promoter can down-regulate the gene expression of the YAP gene for breast cancer patients [23]. In our previous work, we also found that some key hypomethylation sites in enhancer regions and key hypermethylation sites in $\mathrm{CpG}$ islands are used to regulate the expression of key genes, such as oncogenes ESR1 and ERBB2, and TSGs FBLN2, CEBPA, and FAT4 [24].

However, despite the significant progress were made in the methylation changes of breast cancer, many questions remain unanswered. Here, we explored the relationship between abnormal DNA methylation in different regions and the differential expressions of genes and found the key regions where DNA methylation abnormalities lead to changes in gene expression. Finally, we discovered 18 key genes related to breast cancer and confirmed that the genes are related to the prognosis of breast cancer.

\section{Results}

\section{Abnormal DNA methylation distribution in up-regulated hypomethylation and down-regulated hypermethylation genes}

The study design flowchart is shown in Fig. 1a. By analyzing gene expression data, we found that 3741 genes were significantly up-regulated, and 2369 genes were significantly down-regulated in breast cancer tissues. By computing the DNA methylation data in the promoter regions of genes, it was found that 2991 genes were hypermethylated and 832 genes were hypomethylated in breast cancer tissues. Because the level of DNA methylation in the promoter region has a negative regulatory effect on gene expression [25], therefore, through the intersection of genes, we found that 171 genes were up-regulated and hypomethylated (U-Hypo), 612 genes were down-regulated and hypermethylated (D-Hyper) in breast cancer tissues (Fig. 1b).

To understand the DNA methylation characteristics of these genes and whether DNA methylation has also changed in other regions, we analyzed DNA methylation distribution in the enhancer, promoter, 5 'UTR, exon, intron, 3'UTR, and intergenic regions of U-Hypo and D-Hyper genes between cancer and paracancerous tissues (Fig. 2). It can be seen from Fig. 2a, there were no significant changes of the DNA methylation levels in the exons, introns, 3'UTR, and intergenic regions between cancer tissues and paracancerous tissues. The methylation levels in the promoter regions and 5'UTR regions of the D-Hyper genes were significantly higher in cancer tissue than that in paracancerous tissues. Notably, there were significant differences in the 22nd bin $(-400 \mathrm{bp}$, $-300 \mathrm{bp})$, 24th bin $(-200 \mathrm{bp},-100 \mathrm{bp})$ and 26th bin (0 bp, 100 bp) regions near TSS, and the most difference of methylation occurs in the 24th bin $(-200 \mathrm{bp}$, $-100 \mathrm{bp})$. As it can be seen from Fig. 2b, the U-Hypo genes also showed a significant difference of methylation occurs in the promoter and the 5'UTR regions, but the methylation level of the cancer tissues was lower than the methylation level of the paracancerous tissues. The most obvious difference occurs in the 26th bin ( $0 \mathrm{bp}, 100 \mathrm{bp}$ ) of the promoter region.

To further investigate the effect of DNA methylation in the promoter and 5'UTR region on gene expression, we calculated the relative difference of DNA methylation between cancer tissues and paracancerous tissues for each bin in each D-Hyper or U-Hypo gene, and results were shown by heat maps (Fig. 2c, d, e, and f). Abnormal DNA methylations were mainly enriched in $14 \sim 17$ th bins ( $-200 \mathrm{bp}, 200 \mathrm{bp}$ ) of the promoter region

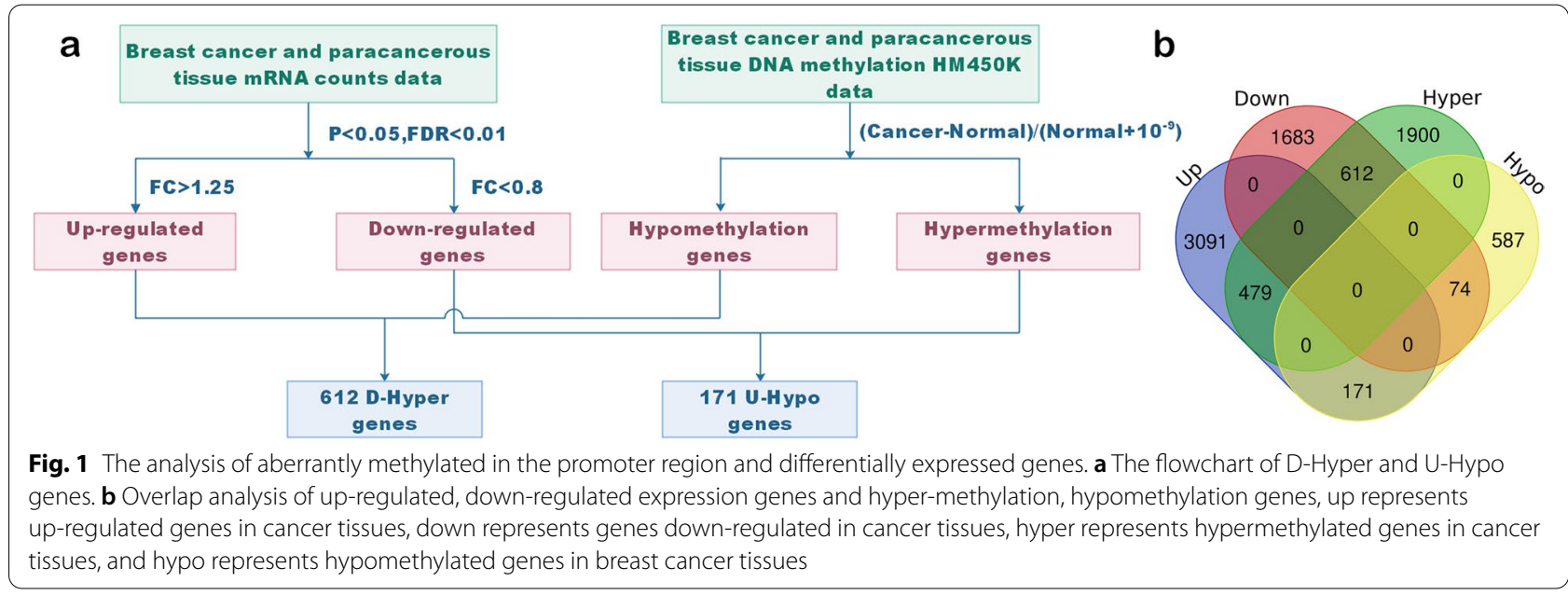




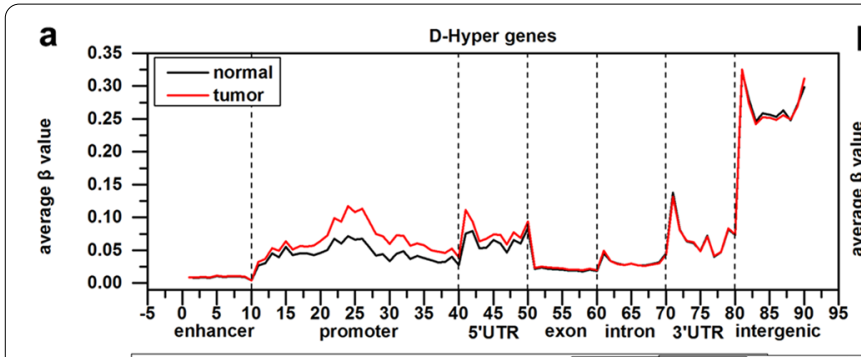

C
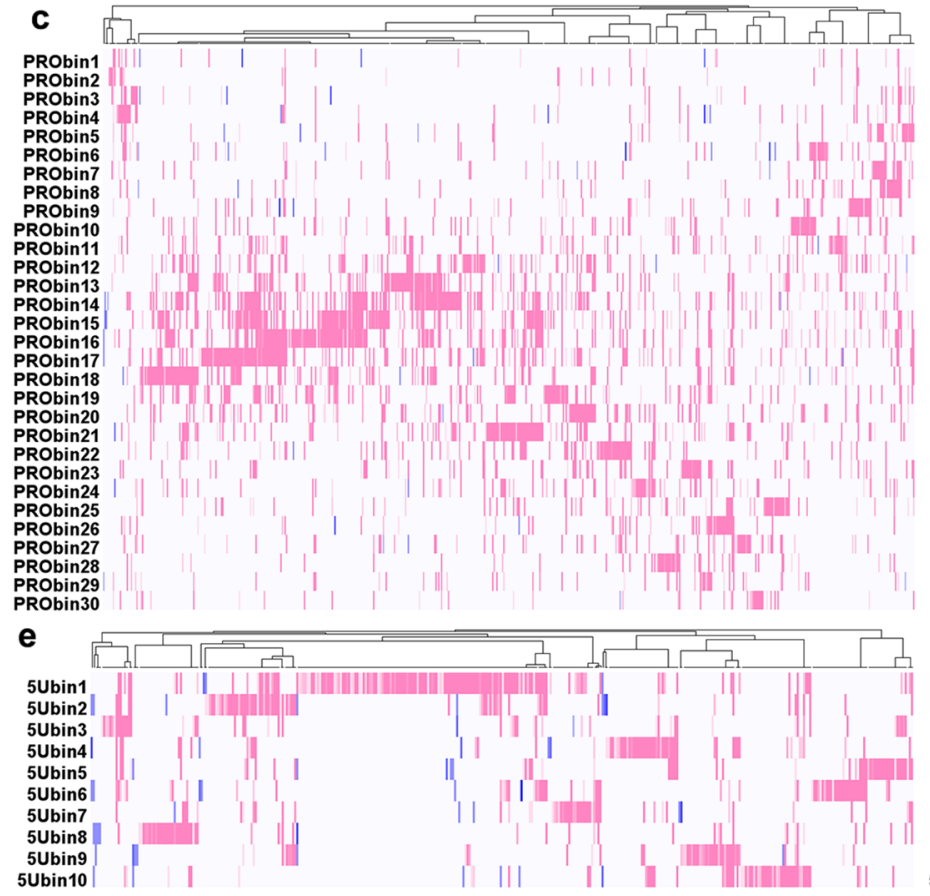

g

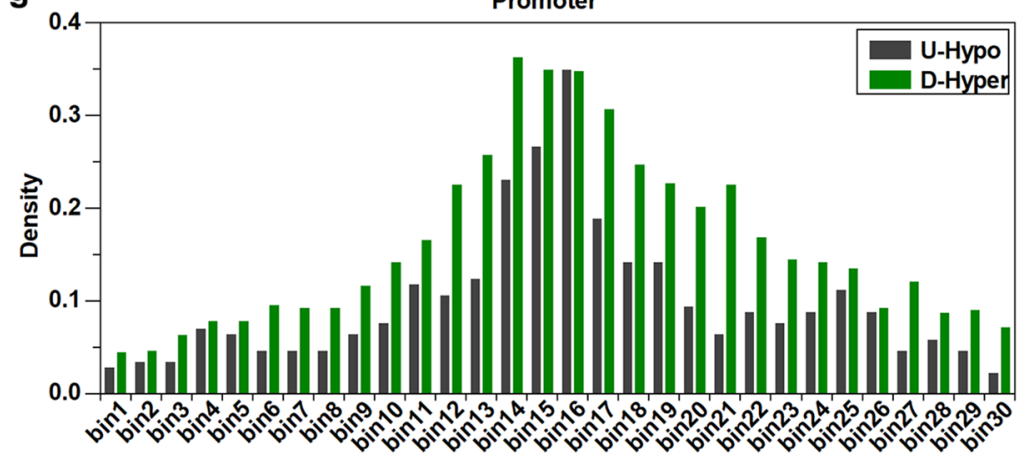

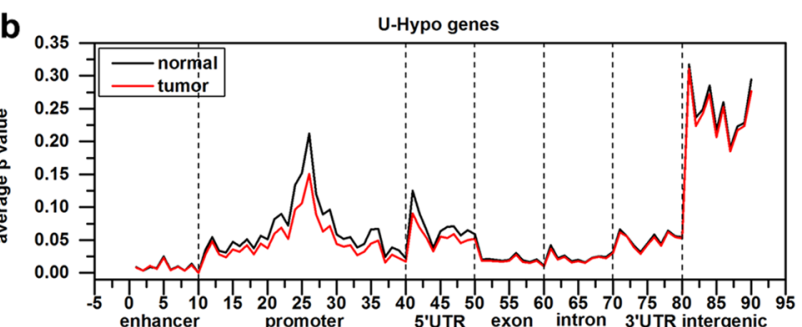

d

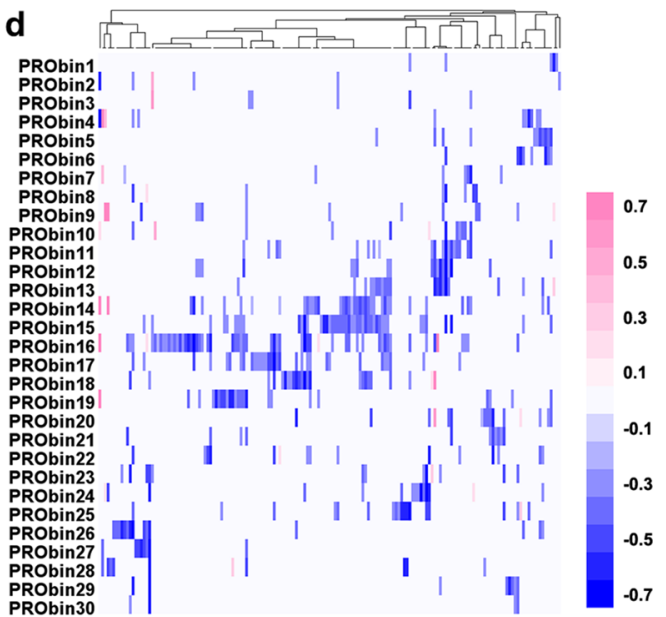

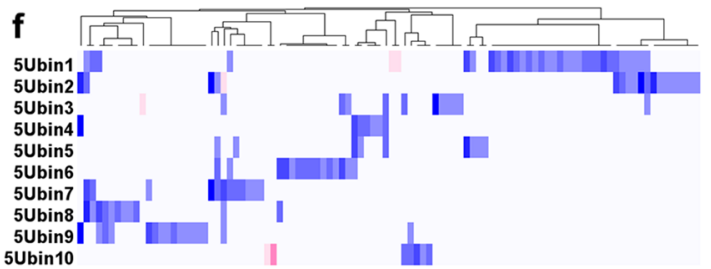

h

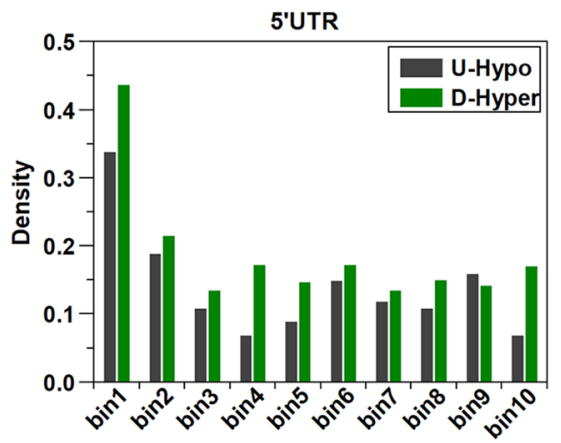

Fig. 2 DNA methylation profiles of 612 D-Hyper, 171 U-Hypo genes. $\mathbf{a}, \mathbf{b}$ The distribution of DNA methylation in the functional regions of D-Hyper, $\mathrm{U}$-Hypo genes, respectively. Wherein the ordinate is the average $\beta$ value of the CpG site in each bin, and the abscissa is the bin of each functional region. $\mathbf{c}$, d The distribution of $R D$ value in the promoter $(\mathrm{PRO})$ of the $\mathrm{D}$-Hyper and the $\mathrm{U}$-Hypo genes. $\mathbf{e}$, $\mathbf{f}$ The distribution of $R D$ value in the $5^{\prime} U T R$ $(5 \mathrm{U})$ region of the D-Hyper and the U-Hypo genes. Pink means that the DNA methylation value in breast cancer tissues is higher than that in paracancerous tissues, and blue opposite. $\mathbf{g}, \mathbf{h}$ The distribution density of aberrant methylation genes in the promoter and 5'UTR regions

for the D-Hyper genes and the U-Hypo genes (Fig. 2c, $\mathrm{d}$, and g), indicating the DNA methylation in $200 \mathrm{bp}$ upstream and downstream of TSS have the obvious difference between cancer tissues and paracancerous tissues. In the 5'UTR region (Fig. 2e, $\mathrm{f}$, and h), the main changes of DNA methylation were significantly enriched in the 1st bin for the D-Hyper genes and the U-Hypo genes. 


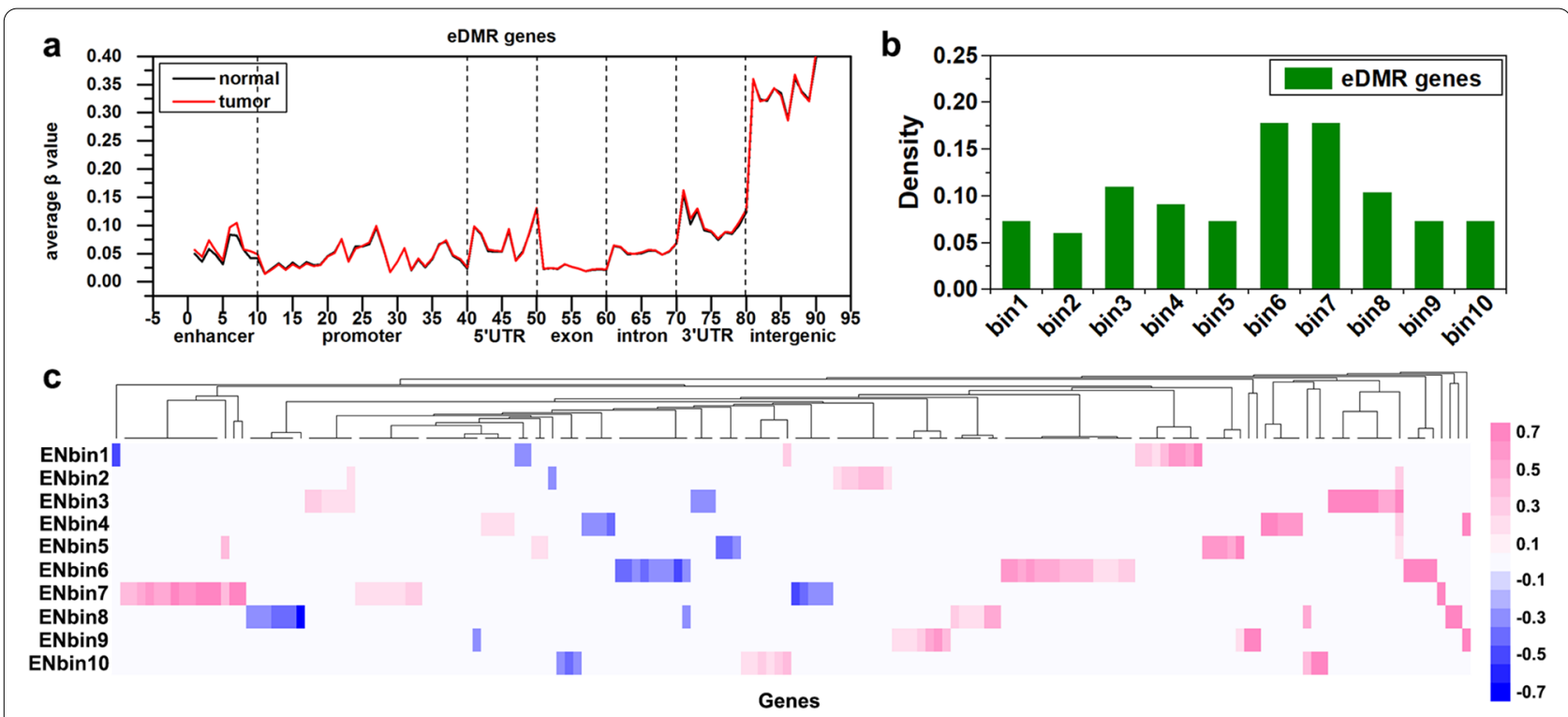

Fig. 3 DNA methylation profiles of DME genes. a The distribution of DNA methylation in the functional regions of the DME gene set, wherein the ordinate is the average $\beta$ value of the $\mathrm{CpG}$ site in each bin, and the abscissa is the bin of each functional region. $\mathbf{b}$ The distribution density of aberrant methylation in the enhancer. $\mathbf{c}$ The distribution of $R D$ value in the enhancer (EN) of DME genes

\section{The characteristics of abnormal methylation} in differentially methylated enhancers (DME) genes

To study the effect of the DNA methylation level in specific regions of enhancers on the gene expression in breast cancer. By using a comprehensive model (Fig. 8), we selected genes (162 DME-gene pairs) with abnormal DNA methylation in the enhancer region, while no abnormal DNA methylation in the promoter region, and the abnormal DNA methylation in the enhancer region is negatively correlated with gene expression (Supplementary Table). Since some genes are regulated by multiple enhancers, 162 DME-gene pairs are corresponding to 154 genes.

To understand the DNA methylation characteristics in the enhancer and other regions of the DME genes, we analyzed the DNA methylation profile of the 154 DME genes. We could conclude that the DNA methylation was different in the enhancer region of DME genes, but the level of DNA methylation had no significant difference in other regions between breast cancer and paracancerous tissues (Fig. 3a). From the differential DNA methylation gene density distribution of the enhancer region, it can be seen that the differential methylation of DME genes was mainly enriched in the 6th and 7th bins (Fig. 3b). Further, we analyzed the differential methylation levels of each bin of the enhancer region in DME genes. There were more hypermethylated genes than the hypomethylated genes, and the differential methylation was enriched in the 6th and 7 th bins (Fig. 3c). Therefore, we can conclude that abnormal DNA methylation in the 6th and 7th bins of the enhancer region affects the expression of the DME gene.

\section{GO, KEGG analysis of D-Hyper, U-Hypo, and DME genes}

To explore the potential biological functions of D-Hyper, U-Hypo, and DME genes, we performed GO function and KEGG pathway analysis. The GO analysis results showed that D-Hyper genes are related to the cell-cell adhesion via plasma-membrane adhesion molecules, regulation of system process, ion channel activity, RNA polymerase II regulatory region DNA binding, and growth factor binding, etc. The analysis of the KEGG pathway revealed that these genes were significantly enriched in Neuroactive ligand-receptor interaction, Oxytocin signaling pathway, and Pathways in cancer, etc. (Fig. 4). For U-Hypo genes, it was mainly related to the cytokine-mediated signaling pathway and the regulation of gene silencing. Transcriptional misregulation in cancer and the IL-17 signaling pathway are pathways associated with potential oncogenes (Supplementary Figure 1). The DME genes were mainly associated with the regulation of the ERBB signaling pathway, the negative regulation of cell differentiation, and the negative regulation of cell proliferation, etc. Through the KEGG pathway analysis revealed that the DME genes are enriched in pathways such as Focal adhesion, Viral carcinogenesis, and Melanoma (Supplementary Figure 2). These analyses suggested that the three kinds of the gene are relevant to cancer. 


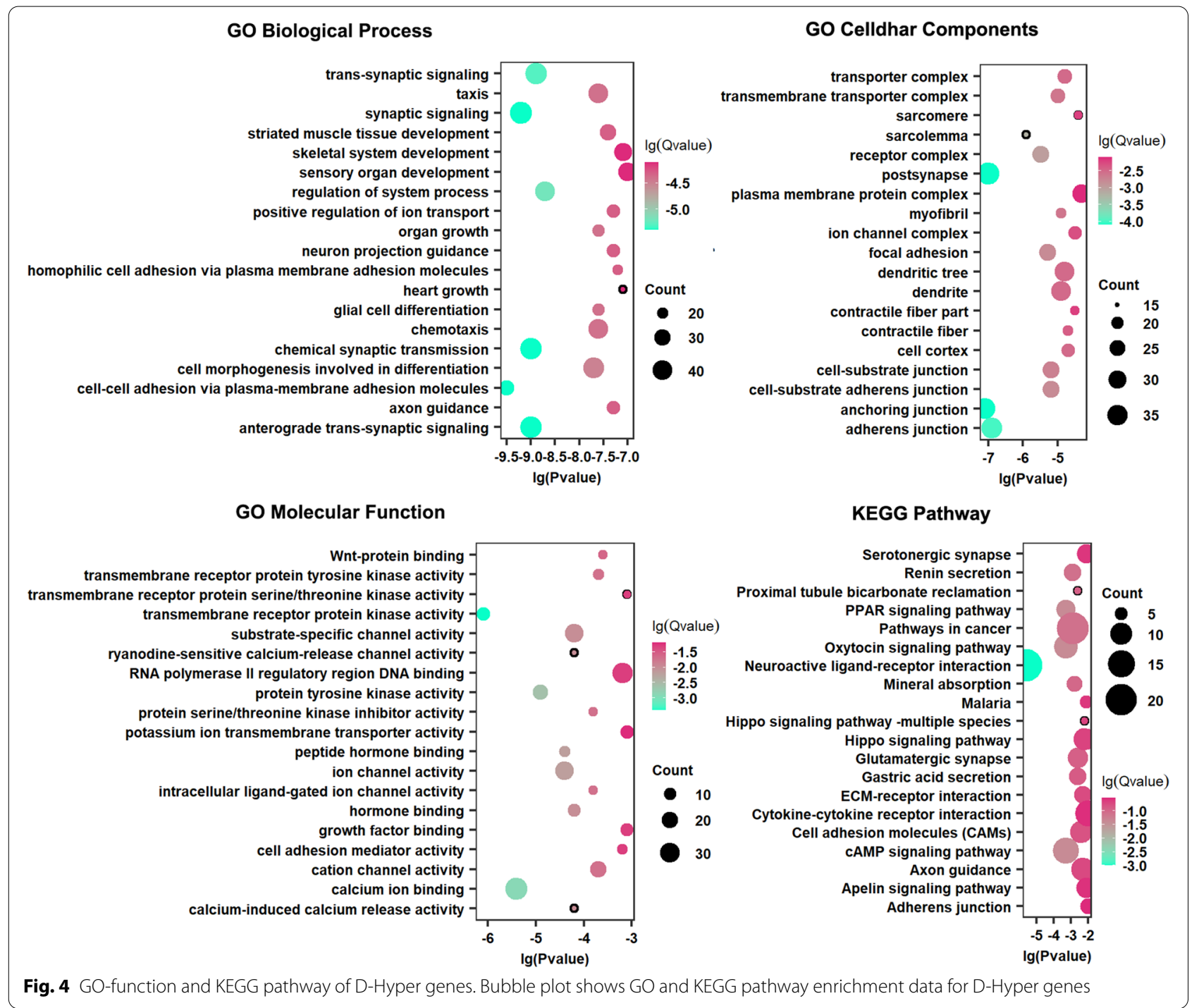

\section{The key genes related to breast cancer}

In order to further explore the DNA methylation distribution characteristics of oncogenes and TSGs, we intersect D-Hyper, U-Hypo, DME genes with cancer-related gene sets, respectively, and obtained 41 oncogenes and 91 TSGs. By analyzing the DNA methylation distribution of these genes, it can be seen that abnormal DNA methylation in the promoter region was still significantly enriched in 14 17th bins ( $-200 \mathrm{bp}, 200 \mathrm{bp}$ ) (Fig. 5a). Therefore, we further selected the genes of abnormal DNA methylation in the promoter 14 17th bins ( -200 bp, $200 \mathrm{bp}$ ) (Fig. 5b and c). Then by analyzing the GO and KEGG pathways of these genes, 20 key genes related to breast cancer were finally obtained, including 19 TSGs $(A C V R 2 A$, CAV1, EGFR, FAT4, ID1, ID4, KIT, LEP, LEPR, MET, NRG1, PPARG, PRDM16, PREX2, PROX1, RYR3, SOX17, STAT5A, VIM) and 1 oncogene (PLK1).

\section{The analysis of DNA methylation and gene expression} for key genes in large samples

To verify whether the 20 key genes had the same pattern in large samples, we analyzed DNA methylation data and gene expression data from breast cancer samples in TCGA. The genes expression levels $\left(\log _{2}\right.$ (FPKM)) of 20 are shown in Fig. 6a, it can be seen that the expression levels of the 19 genes were higher in the paracancerous tissues than in breast cancer tissues, except that the expression level of the PLK1 was lower in the paracancerous tissues than in breast cancer tissues. It could be concluded that PLK1 acts as an oncogene in breast cancer, while the remaining 19 genes acted to inhibit tumors. Figure $6 \mathrm{~b}$ and $\mathrm{c}$ show the distribution of abnormal DNA methylation in the promoter regions of the 20 key genes in the large samples. The results indicated that only the 29th bin in the promoter region of the PLK1 gene was 


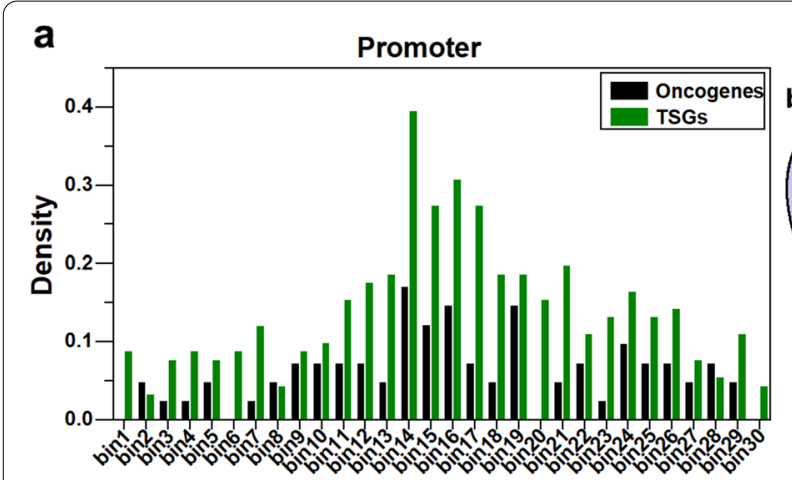

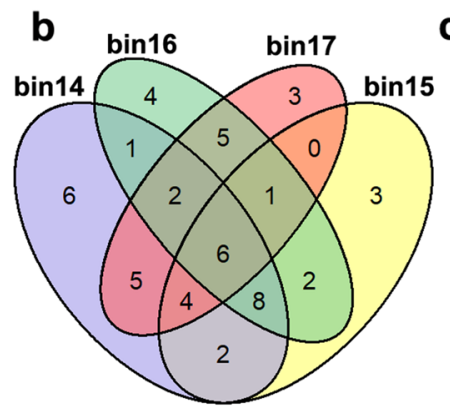

Tumor suppressor genes

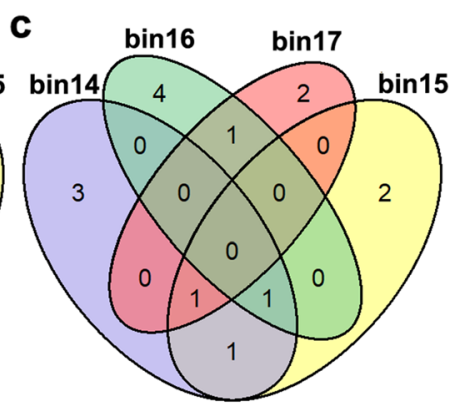

Oncogenes

Fig. 5 The distribution in promoter region for TSGs and oncogenes. a The distribution of density in promoter region for TSGs (tumor suppressor genes) and oncogenes. $\mathbf{b}$ and $\mathbf{c}$ is the number of the tumor suppressor genes and oncogenes for abnormal DNA methylation in the promoter $14 \sim 17$ th bins

abnormally hypomethylated, while other genes were abnormally hypermethylated (Fig. 6b). Figure 6c shows that abnormal DNA methylation in the promoter region was mainly enriched in $14 \sim 17$ th bins ( $-200 \mathrm{bp}, 200 \mathrm{bp}$ ). These are consistent with the conclusions we have drawn in the small sample.

\section{Survival analysis of key genes}

To further verify the influence of the expression for the above 20 key genes on breast cancer, we used KM plotter to perform Kaplan-Meier survival analysis of these key genes to determine the prognostic value of these key genes in breast cancer. Figure 7 shows survival curves for all breast cancer patients $(n=4929)$. It can be seen that the high expression of PLK1 was associated with poor overall survival of breast cancer patients. This result further indicated that PLK1 was an oncogene. In contrast, the high expression of the 17 genes (EGFR (211550_at), ACVR2A (205327_s_at), CAV1 (203065_s_at), FAT4 (219427_at), ID1 (208937_s_at), ID4 (209292_at), KIT (205051_s_at), LEPR (207255_ at), MET (213816_s_at), NRG1 (208241_at), PPARG (208510_s_at), PRDM16 (220928_s_at), PREX2 (220732_at), PROX1 (207401_at), RYR3 (206306_at), SOX17 (219993_at), and STAT5A (203010_at)) could significantly improve the prognosis of breast cancer patients. However, the high expression of LEP (207092_ at) and VIM (201426_s_at) were weakly correlated with a good prognosis. It has been proved that 17 TSGs and 1 oncogene can be used as the markers of the prognosis for breast cancer patients.

\section{Discussion}

Based on the analysis of the genome DNA methylation profiles for differentially expressed genes and DME genes, the results indicated that the most of hyper- and hypo- DNA methylation sites were located in the $14 \sim 17$ th bins ( $-200 \mathrm{bp}, 200 \mathrm{bp})$. Furthermore, we identified 1 oncogene and 17 TSGs as potential biomarkers for breast cancer diagnostic.

In addition, we further confirmed the selected TSGs and oncogenes are associated with breast cancer. We found that EGFR, NRG1, and STAT5A were enriched in the ErbB signaling pathway, ID1 and ID4 were enriched in the Hippo signaling pathway, EGFR, KIT, and MET were enriched in the PI3K-Akt signaling pathway and SOX17 was enriched in the Wnt signaling pathway. These pathways related to environmental information processing and signal transduction had been shown to be closely related to the occurrence of breast cancer and play a decisive role [24, 26-29]. EGFR, KIT, MET, PPARG, and STAT5A were enriched in the Pathways in cancer, $C A V 1, E G F R$, and $M E T$ were enriched in the Proteoglycans in cancer, and MET and PPARG were enriched in the Transcriptional misregulation in cancer. These pathways play a very important role in most human cancers $[26,30]$. These findings further indicate that these genes can be used as biomarkers for breast cancer. In addition, $A C V R 2 A, I D 1$, and ID4 are enriched in the TGF $-\beta$ signaling pathway, and the role of TGF- $\beta$ in osteolytic bone metastasis was well known [31, 32]. The GO biological processes of ACVR2A, KIT, and FAT4 are skeletal system development, $R Y R 3$ and EGFR are in the Calcium signaling pathway enrichment, the GO molecular functions of $R Y R 3$ and FAT4 are calcium ion binding and the GO molecular function of RYR3 is calcium-induced calcium release activity [33], and the most common metastasis of breast cancer is bone metastasis, so the enrichment of these GO biological processes, GO molecular functions and key pathways seems to explain why $85 \%$ of patients with advanced breast cancer have bone metastases [31, 34]. 


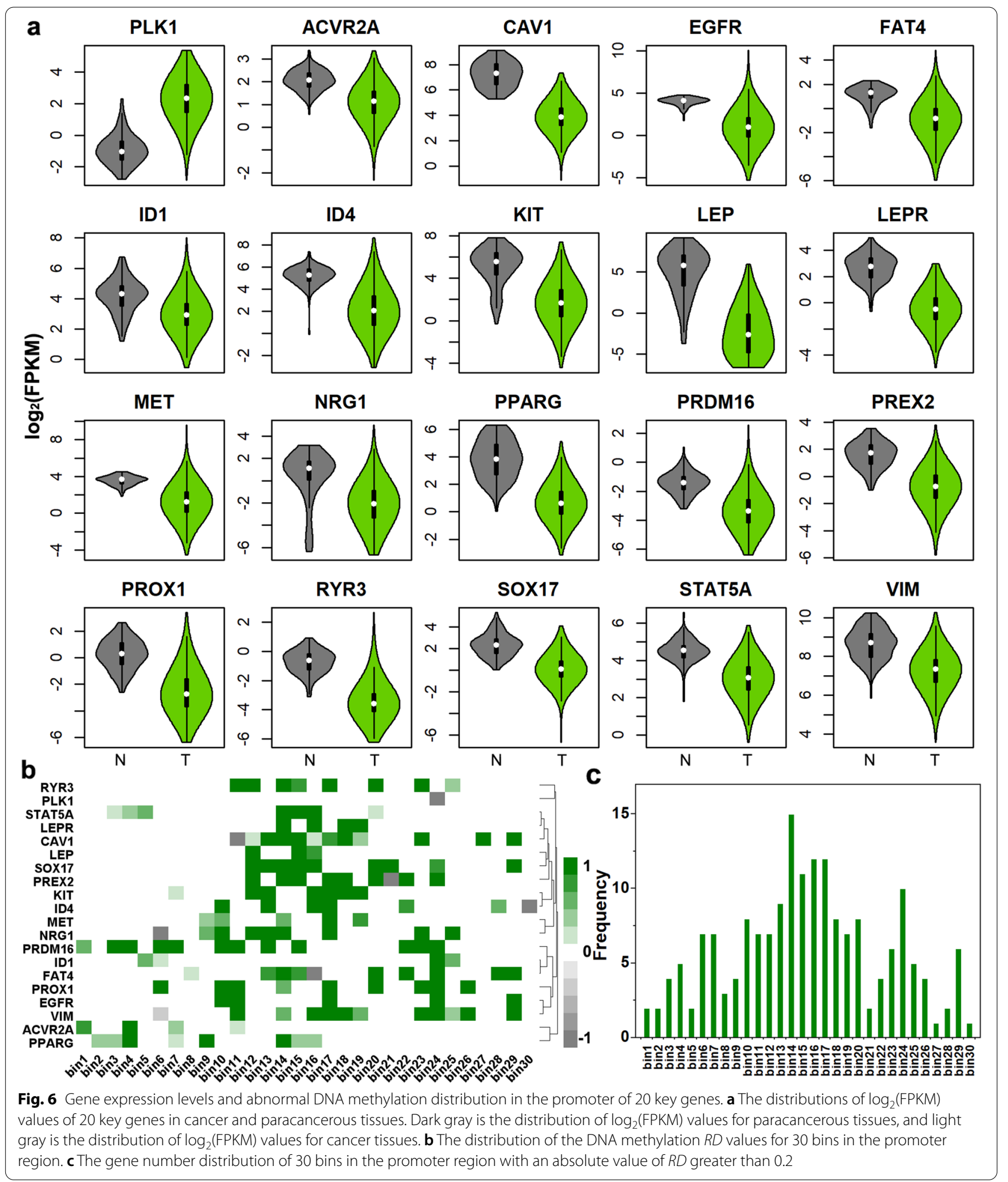

\section{Conclusions}

In this study, we found that the abnormal DNA methylation of TSGs and oncogenes associated with the pathogenesis of breast cancer is mainly concentrated in the TSS $\pm 200 \mathrm{bp}$ region. we obtained 17 TSGs and 1 oncogene associated with breast cancer, and verified 

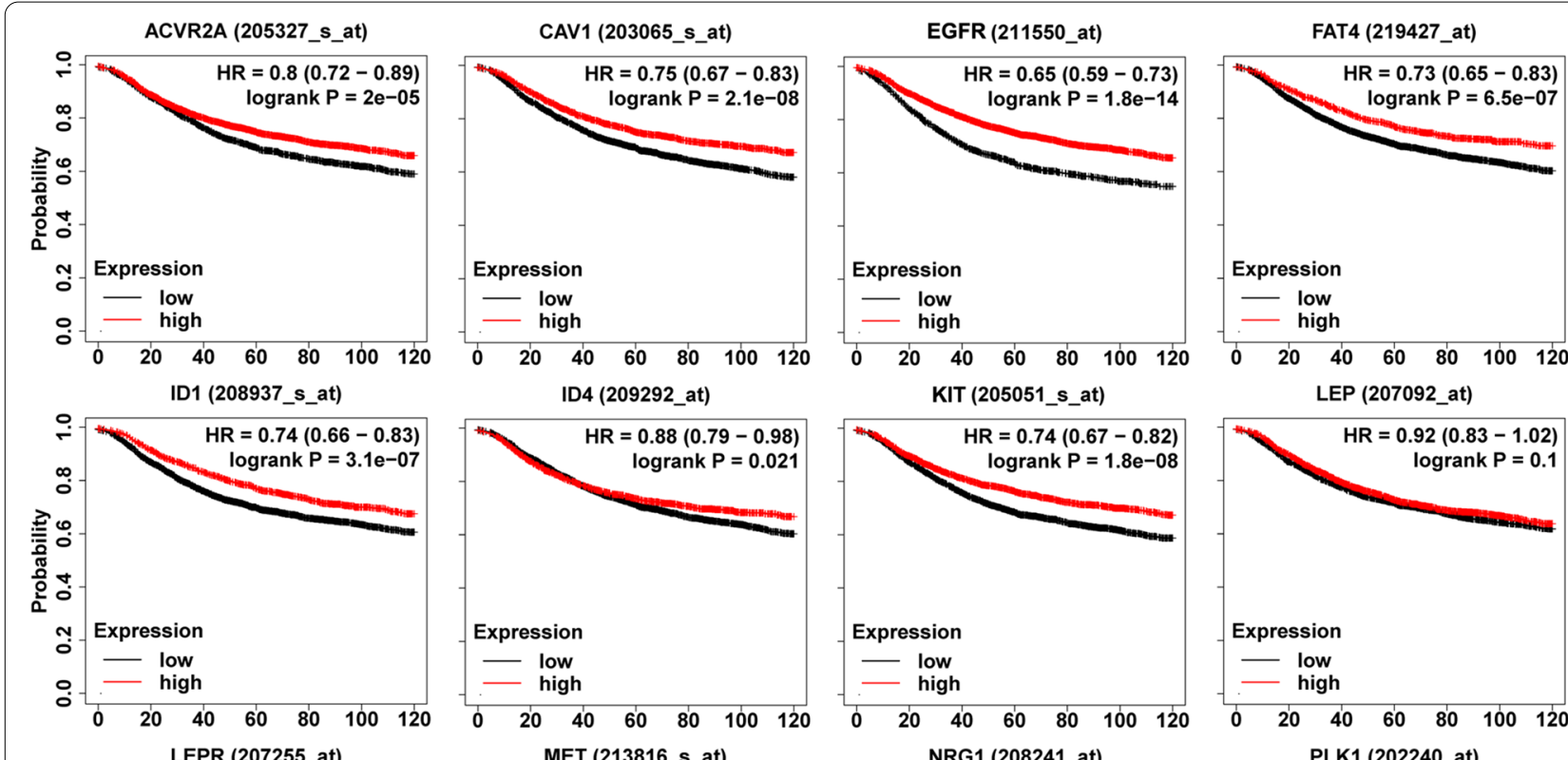

KIT (205051_s_at)

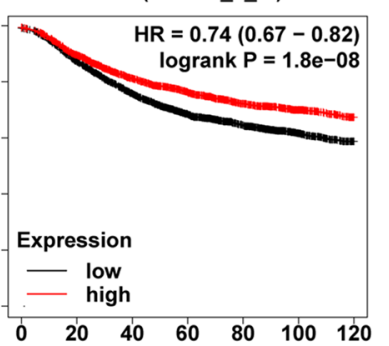

LEP (207092_at)

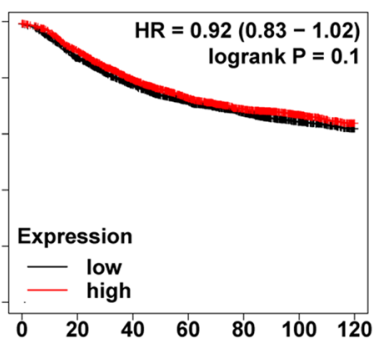
NRG1 (208241_at)
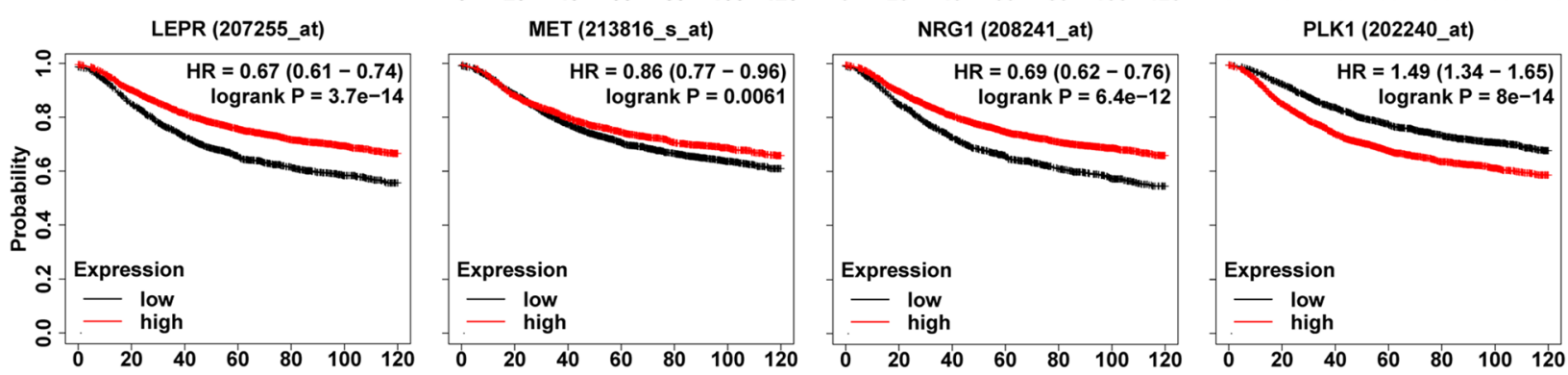
PRDM16 (220928_s_at)
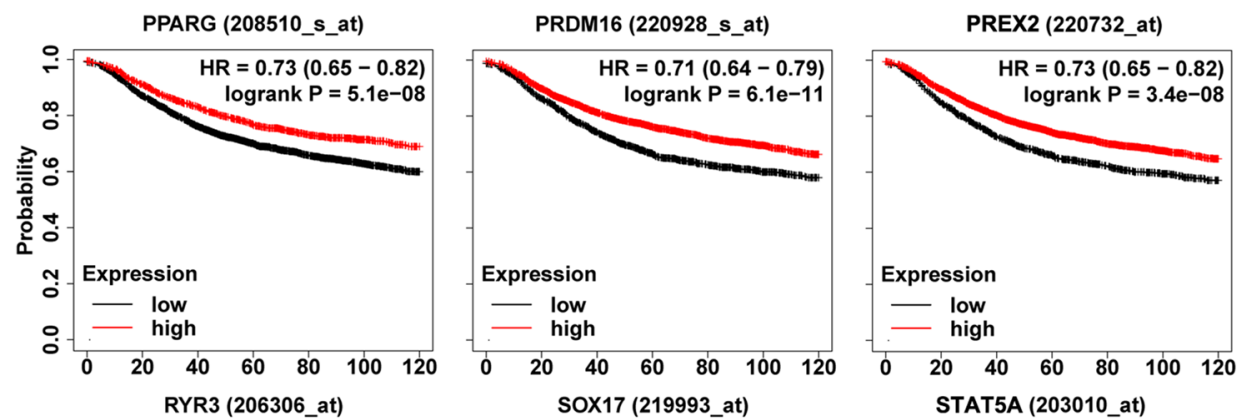
PROX1 (207401_at)

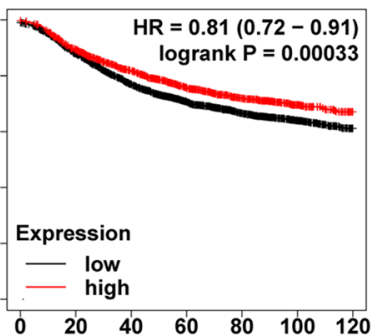
SOX17 (219993_at)
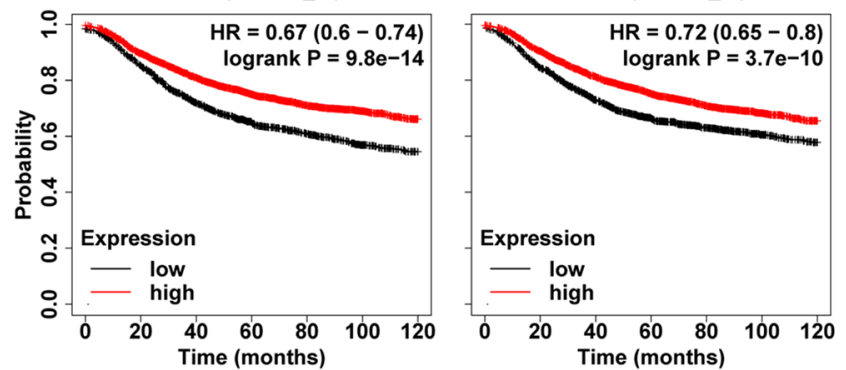

STAT5A (203010_at)

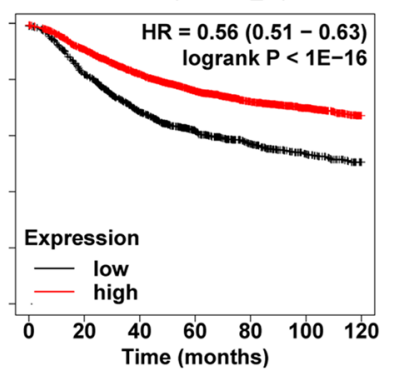

$\begin{array}{lllllll}0 & 20 & 40 & 60 & 80 & 100 & 120\end{array}$ VIM (201426_s_at)

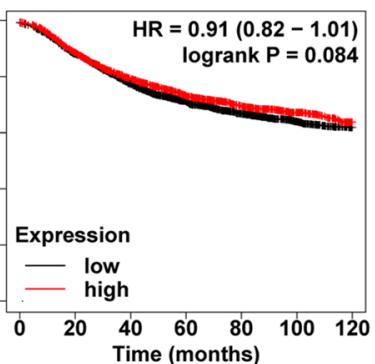

Fig. 7 The effect of changes in expression levels of the 20 key genes on overall survival. The KM plotter of these key genes. The name of each figure is the gene symbol and Affymetrix ID. The abscissa is the survival time, the unit is the month, and the ordinate is the survival rate 
Table 1 The details of 1097 breast cancer samples data types

\begin{tabular}{lll}
\hline Type & DNA methylation & $\begin{array}{l}\text { Gene expression } \\
\text { (FPKM and } \\
\text { COUNTS) }\end{array}$ \\
\hline Paracancerous sample & 96 & 113 \\
Cancer sample & 789 & 1097 \\
\hline
\end{tabular}

them by survival analysis. Our results may provide help for studying, the pathogenesis of breast cancer, potential therapeutic targets, and epigenetic modification as novel target drugs.

\section{Materials and methods}

\section{Data sources}

We downloaded the DNA methylation (Illumina Infinium Human Methylation 450K) data and gene expression data (FPKM and COUNTS) of 1097 breast cancer samples from TCGA (https://tcga-data.nci.nih.gov/tcga/) (Table 1). There were 9 breast cancer samples that contain breast cancer tissue and matched paracancerous tissue data. The RefSeq genes of the human genome (hg38) were downloaded from the University of California Santa Cruz (UCSC) (http://genome.ucsc.edu/). The Ensemble Gene ID (GRCh38) annotation file and the location file of the human breast tissue enhancer were downloaded from Ensembl (http://www.ensembl.org/Homo_sapiens/).

We obtained a cancer genes sets associated with breast cancer from the Catalogue Of Somatic Mutations In Cancer (COSMIC) (https://cancer.sanger.ac. uk/census) [35], the Candidate Cancer Gene Database (CCGD) (http://ccgd-starrlab.oit.umn.edu/download. php) [36], the Disease-gene associations mined from literature (DISEASES) (https://diseases.jensenlab.org) [37] and the National Cancer Institute (NCI) (https:// wiki.nci.nih.gov/x/hC5yAQ).

\section{Selection of differentially expressed genes}

To obtain the differentially expressed genes between the paracancerous tissue and the cancer tissue, first, we standardized the expression data used the following formulas.

$$
N C_{k j}=R\left(C_{k j} / s_{j}\right) \quad(1 \leq k \leq m, 1 \leq j \leq n)
$$

where

$$
\begin{aligned}
& s_{j}=e^{\eta_{j}} \\
& \eta_{j}=M\left(d_{1 j}, d_{2 j}, \cdots, d_{k j}\right) \\
& d_{k j}=\ln C_{k j} / \sqrt[n]{\prod_{j=1}^{n} C_{k j}}
\end{aligned}
$$

Here $k$ is the $k$-th gene, $j$ is the $j$-th sample, $N C_{k j}$ denotes the normalized expression value of the $k$-th gene in the $j$-th sample, $R$ denotes the rounding, $C_{k j}$ is the gene expression counts of the $k$-th gene in the $j$-th sample, $s_{j}$ is the standardization factor of the $j$-th sample, $m(m=60,483)$ is the total number of genes, and $n$ $(n=1210)$ is the total number of samples, $M$ denotes to take the median.

Then, using the DESeq function to calculate the differential expression of gene, got the $\log$ 2(FoldChange), pval ( $p$ value for the statistical significance of this change) and padj ( $\mathrm{p}$ value adjusted for multiple testing with the Benjamini-Hochberg procedure) [38]. Among them, Fold Change $(F C)$ was calculated as follows:

$$
F C_{k}=\frac{\sum_{j=1}^{n_{t}} N C_{k j, t}}{n_{t}} / \frac{\sum_{j=1}^{n_{p}} N C_{k j, p}}{n_{p}}
$$

Here, $k$ and $j$ are the same as Eq. (1), $t$ is the cancer sample, $p$ is the paracancerous sample, $N C_{k j, t}\left(N C_{k j, p}\right)$ is the normalized expression value of the $k$-th gene in the $j$-th cancer sample (paracancerous sample), $n_{t}\left(n_{t}\right.$ $=1097)$ is the number of the cancer sample, $n_{p}\left(n_{p}=\right.$ $113)$ is the number of the paracancerous sample. $F C_{k}$ denotes the fold change of the $k$-th gene, when $F C_{k}$ $>1.25$, padj $<0.05$ as up-regulated expression genes, and $F C_{k}<0.8$, padj $<0.05$ as down-regulated expression genes.

\section{Selection of differential DNA methylation genes}

The DNA methylation levels of DNA methylation HM450K data were measured by the value of each probe. The degree of methylation $(\beta)$ was defined as follows:

$$
\beta_{i}=\frac{\max \left(y_{i, \text { methy }}, 0\right)}{\max \left(y_{i, \text { methy }}, 0\right)+\max \left(y_{i, \text { umethy }}, 0\right)+\alpha}\left(1 \leq i \leq m_{w}\right)
$$

Where $i$ is the $i$-th CpG probe, $m_{w}\left(m_{w}=485,578\right)$ is the total number of the probes, $\max \left(y_{i, \text { methy }}, 0\right)$ and $\max \left(y_{i, \text { umethy }}, 0\right)$ are the signal intensities of the methylated and unmethylated for the $i$-th probe, respectively. The $\alpha$ is a constant (the default value is set to 100) to eliminate the effect on the $\beta$ value when the $\max \left(y_{i}\right.$, methy, 0$)$ and $\max \left(y_{i}\right.$, umethy, 0$)$ are simultaneously low [39]. There are 485,578 probes in the file of the DNA methylation data, and 482,421 CpG probes were left after the non-CpG probes were removed. There are many "NA"s in the column due to the presence of single nucleotide polymorphisms (SNPs) [40]. Further, 96,079 probes containing "NA" were deleted. Finally, 386,342 probes remained.

We matched these probes to the promoter region (1500 bp upstream and downstream of TSS) of 18,861 
genes, and calculated the DNA methylation level of genes according to the following formula.

$$
\begin{aligned}
& \beta_{k, S}=\frac{\sum_{i=1}^{m_{r}} \beta_{i, S}}{m_{r}}\left(1 \leq i \leq m_{r}, S=t, p\right) \\
& \beta_{i, S}=\frac{\sum_{j=1}^{n_{S}} \beta_{i j, S}}{n_{S}}\left(1 \leq j \leq n_{S}\right)
\end{aligned}
$$

Here $i$ is the same as Eq. (4), $k$ and $j$ are the same as Eq. (1), $S$ is the sample type, $t$ is the cancer sample, $p$ is the paracancerous sample, $m_{r}$ is the number of probes falling into the promoter region for the $k$-th gene, $\beta_{i, S}$ is the average DNA methylation value of the $i$-th probe in the cancer sample (paracancerous sample), $\beta_{k, S}$ is the DNA methylation level of the $k$-th gene in the cancer sample (paracancerous sample), $\beta_{i j, s}$ denotes the DNA methylation level of the $i$-th probe in the $j$-th cancer sample (paracancerous sample), $n_{S}$ is the total number of sample $\left(n_{t}\right.$ $=789, n_{p}=96$ ).

The genes of differential DNA methylation were defined by using relative difference $(R D)$ [41]. The formula was as follows:

$$
R D_{k}=\frac{\beta_{k, t}-\beta_{k, p}}{\beta_{k, p}+\Delta}\left(1 \leq k \leq m_{g}\right)
$$

Here $k$ is the $k$-th gene, $R D_{k}$ is the relative difference of DNA methylation in the $k$-th gene, $\beta_{k, t}$ and $\beta_{k, p}$ denotes the average DNA methylation level of the $k$-th gene in the cancer sample and paracancerous sample, respectively. $\Delta=10^{-9}, m_{g}\left(m_{g}=18,861\right)$ is the total number of the genes. When $R D_{k}>0.2$, the DNA methylation level of this gene is higher in breast cancer tissues than that in paracancerous tissues, we defined it as a hypermethylated gene; when $R D_{k}<-0.2$, the DNA methylation level of this gene is lower in breast cancer tissues than that in paracancerous tissues, we defined it as a hypomethylated gene.

\section{Calculation of DNA methylation levels in different regions}

First, we used the file of tissue-specific gene regulatory location in the Ensembl database to extract the enhancer region. And according to the RefSeq annotation file, we divided the gene into the following regions: (1) promoter (TSS $\pm 1500 \mathrm{bp}$ ), (2) 5'UTR, (3) exon, (4) intron,

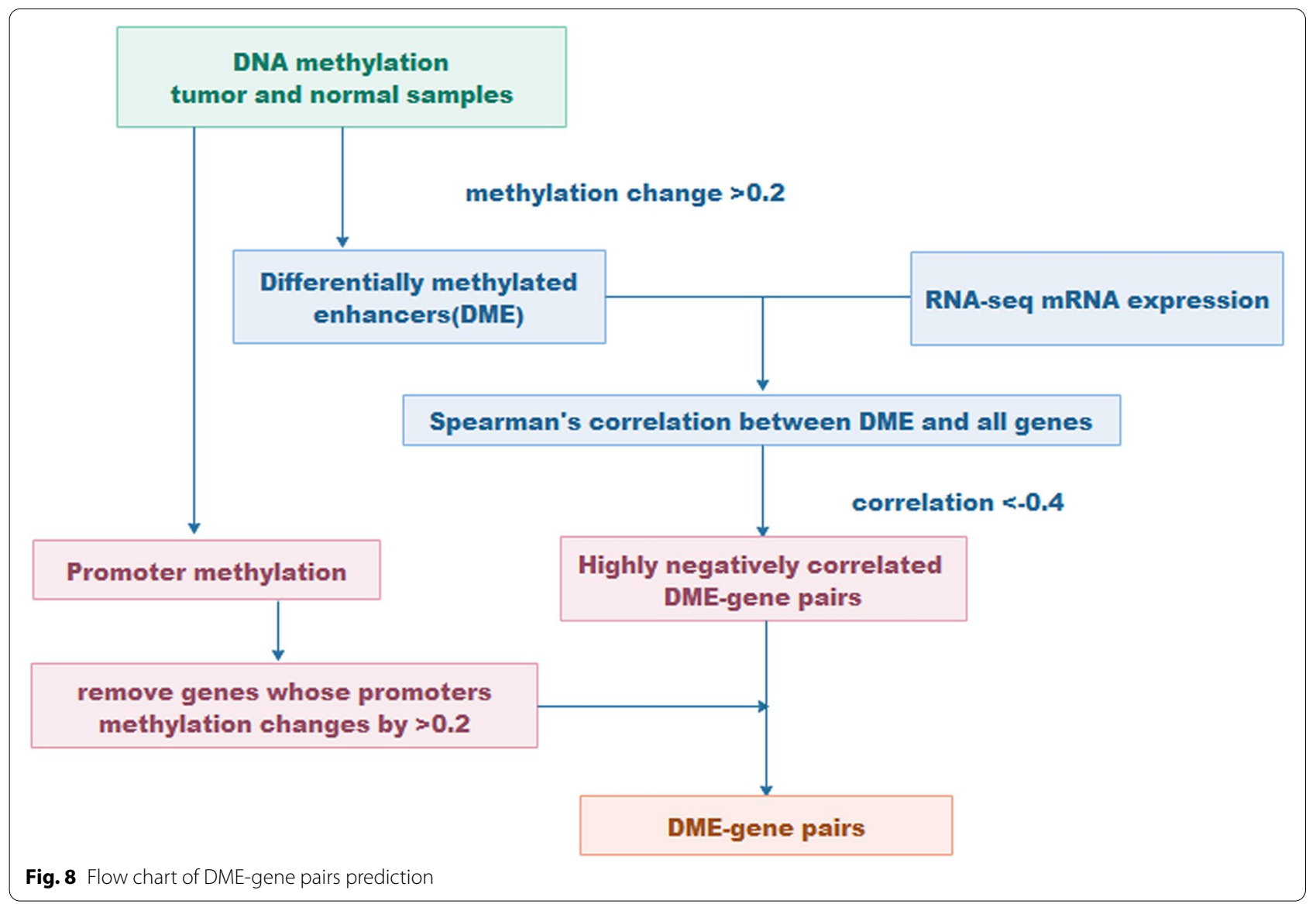


(5) 3'UTR, (6) intergenic region. Second, the promoter region was divided into 30 bins, each bin was $100 \mathrm{bp}$, and the other genomic functional regions were divided into 10 bins, respectively. Third, the CpG site was matched to the bins, the methylation level of each bin was calculated by the following formula:

$$
\beta_{k, S}^{\mu \xi}=\frac{\sum_{i=1}^{m_{r}} \beta_{i, S}}{m_{r}}\left(1 \leq i \leq m_{w}, 1 \leq \mu \leq m_{b}, 1 \leq k \leq m_{g}, S=t, p\right)
$$

Here $k, i$, and $\beta_{i, S}$ are the same as Eq. (5), $\mu$ is the $\mu$-th bin, $\xi$ is the $\xi$-th region, $m_{w}\left(m_{w}=386,342\right)$ is the total number of probes, $m_{b}\left(m_{b}=10\right)$ is the total number of bins, $m_{g}\left(m_{g}=18,861\right)$ is the total number of genes, $S$ is the sample type, $t$ is the cancer sample, $p$ is the paracancerous sample, $\beta_{k, S}^{\mu \xi}$ is the DNA methylation level of the $\mu$-th bin in the $\xi$-th region for the $k$-th gene. $m_{r}$ is the number of probes falling into the $\mu$-th bin in the $\xi$-th region for the $k$-th gene.

\section{Identifying the target gene of the enhancer and predicting genes regulated by differentially methylated enhancers (DME)}

It is well known that the enhancer is a short (50 1500bp) DNA region upstream or downstream 1Mbp of TSS in the gene $[42,43]$. The enhancer can usually regulate the closest gene. By computing the distance from the TSS of each gene to the center of the enhancer region, and the gene closest to each enhancer was defined as the target gene of the enhancer. A comprehensive model was used for predicting genes regulated by DME (Fig. 8). First, we used Eq. (6) to calculate the differential methylation between the paracancerous tissue and the cancer tissue for the enhancer and promoter regions. Second, Spearman's correlation $\left(r_{k}\right)$ between the relative difference $\left(R D_{k j}\right)$ of the DNA methylation for DME and the differential expression foldchange $\left(F C_{k j}\right)$ for its target gene was calculated in matched patients, and the highly negatively correlated $\left(r_{k}<-0.4\right)$ DME gene pairs were retained. Third, we removed the gene whose differential methylation value is greater than 0.2 in promoter, and obtained the differentially expressed genes only due to methylation changes in enhancer as the DME gene pairs [44]. Among them, the correlation coefficient was calculated using the following formula:

$$
r_{k}=1-\frac{6 \sum_{j=1}^{n}\left[R\left(F C_{k j}\right)-R\left(R D_{k j}\right)\right]^{2}}{n\left(n^{2}-1\right)}\left(1 \leq j \leq n, 1 \leq k \leq m_{g}\right)
$$

Where $k$ and $j$ are the same as Eq. (1), $n(n=9)$ is the total number of samples, $m_{g}\left(m_{g}=1902\right)$ is the total number of the target genes, $R\left(F C_{k j}\right)$ is the rank of differential expression foldchange for the $k$-th DME target gene. $R\left(R D_{k j}\right)$ is the rank of relative difference for methylation in the $k$-th DME.
Gene ontology (GO) function, KEGG pathway, and survival analysis

GO and KEGG pathway enrichment analysis was performed using Metascape (http://metascape.org) [45]. Survival analysis was performed by using Kaplan-Meier Plotter (http://kmplot.com/). The Kaplan-Meier plotter has the information of 54,675 probes on survival using 5143 breast cancer patients with a mean follow-up of 69 months. Gene expression data and over survival (OS) information were downloaded from European Genome-phenome Archive (EGA), Gene Expression Omnibus (GEO), and TCGA [46].

\section{Abbreviations}

D-Hyper: Down-regulated and hypermethylated; eDMR: Differentially methylated enhancers; TSGs: Tumor suppressor genes; TSS: Transcription start site; U-Hypo: Up-regulated and hypomethylated.

\section{Supplementary Information}

The online version contains supplementary material available at https://doi. org/10.1186/s41065-022-00220-5.

Additional file 1: Supplement table. Lists of eDMR-gene pair predictions.

Additional file 2: Supplementary Figure 1. GO-function and KEGG pathway of U-Hypo genes in breast cancer. Supplementary Figure 2. GO-function and KEGGpathway of DME genes in breast cancer.

Acknowledgements

Not applicable.

Authors' contributions

Study concept and design: Yan-Ni Cao, Qian-Zhong Li. Data acquisition: Yan-Ni

Cao, Yu-Xian Liu. Data analysis and interpretation: Yan-Ni Cao, Yu-Xian Liu. Drafting of manuscript: Yan-Ni Cao. Critical revisions: all authors. Final approval: all authors.

\section{Funding}

This work is supported by the National Natural Science Foundation of China [grant nos. 32160216, 31870838, and 61861035].

\section{Availability of data and materials}

We have used the gene expression data, DNA methylation data and clinical data from TCGA database (https://tcga-data.nci.nih.gov/tcga/), known cancer genes from Catalogue Of Somatic Mutations In Cancer (COSMIC) (https:// cancer.sanger.ac.uk/cosmic), the Candidate Cancer Gene Database (CCGD) (http://ccgd-starrlab.oit.umn.edu/download.php), the Disease-gene associations mined from literature (DISEASES) (https://diseases.jensenlab.org), and the National Cancer Institute (NCI) (https://wiki.nci.nih.gov/x/hC5yAQ), the genomic data from the UCSC database (http://genome.ucsc.edu/cgi-bin/ hgTables) and Ensembl (http://www.ensembl.org/Homo_sapiens/), and the location file of enhancer from Ensembl (http://www.ensembl.org/Homo_ sapiens/). These data are publicly available.

\section{Declarations}

Ethics approval and consent to participate Not applicable.

Consent for publication

Not applicable.

Competing interests

The authors declare that there is no conflict of interest. 


\section{Author details}

${ }^{1}$ Laboratory of Theoretical Biophysics, School of Physical Science and Technology, Inner Mongolia University, No.235 West Daxue Street, Saihan District, Hohhot 010021, P.R. China. ${ }^{2}$ The State Key Laboratory of Reproductive Regulation and Breeding of Grassland Livestock, Inner Mongolia University, Hohhot 010070, China

Received: 26 September 2021 Accepted: 29 December 2021 Published online: 21 January 2022

\section{References}

1. Sung H, Ferlay J, Siegel RL, Laversanne M, Soerjomataram I, Jemal A, et al. Global Cancer statistics 2020: GLOBOCAN estimates of incidence and mortality worldwide for 36 cancers in 185 countries. CA Cancer J Clin. 2021. https://doi.org/10.3322/caac.21660.

2. Group EBCTC. Effects of radiotherapy and of differences in the extent of surgery for early breast cancer on local recurrence and 15-year survival: an overview of the randomised trials. Lancet. 2005;366(9503):2087-106.

3. Romond EH, Perez EA, Bryant J, Suman VJ, Geyer CE Jr, Davidson NE, et al. Trastuzumab plus adjuvant chemotherapy for operable HER2-positive breast cancer. N Engl J Med. 2005;353(16):1673-84.

4. Senkus E, Kyriakides S, Ohno S, Penault-Llorca F, Poortmans P, Rutgers E, et al. Primary breast cancer: ESMO clinical practice guidelines for diagnosis, treatment and follow-up. Ann Oncol. 2015;26(suppl_5):v8-v30.

5. Miller KD, Siegel RL, Lin CC, Mariotto AB, Kramer JL, Rowland JH, et al. Cancer treatment and survivorship statistics, 2016. CA Cancer J Clin. 2016;66(4):271-89.

6. Figueroa-Magalhães MC, Jelovac D, Connolly RM, Wolff AC. Treatment of HER2-positive breast cancer. Breast. 2014;23(2):128-36.

7. DeMichele A, Yee D, Berry DA, Albain KS, Benz CC, Boughey J, et al. The neoadjuvant model is still the future for drug development in breast cancer. Clin Cancer Res. 2015;21(13):2911-5.

8. Liu YX, Li QZ, Cao YN, Zhang LQ. Identification of key genes and important histone modifications in hepatocellular carcinoma. Comput Struct Biotechnol J. 2020. https://doi.org/10.1016/j.csbj.2020.09.013.

9. Tang Q, Cheng J, Cao X, Surowy H, Burwinkel B. Blood-based DNA methylation as biomarker for breast cancer: a systematic review. Clin Epigenetics. 2016. https://doi.org/10.1186/s13148-016-0282-6.

10. Leygo C, Williams M, Jin HC, Chan MWY, Chu WK, Grusch M, et al. DNA methylation as a noninvasive epigenetic biomarker for the detection of cancer. Dis Markers. 2017. https://doi.org/10.1155/2017/3726595.

11. Gagliardi M, Strazzullo M, Matarazzo MR. DNMT3B functions: novel insights from human disease. Front Cell Dev Biol. 2018. https://doi.org/10. 3389/fcell.2018.00140.

12. Cao W, Lee H, Wu W, Zaman A, McCorkle S, Yan M, et al. Multi-faceted epigenetic dysregulation of gene expression promotes esophageal squamous cell carcinoma. Nat Commun. 2020. https://doi.org/10.1038/ s41467-020-17227-z.

13. Baylin SB, Jones PA. A decade of exploring the cancer epigenome-biological and translational implications. Nat Rev Cancer. 2011;11(10):726-34.

14. Hon GC, Hawkins RD, Caballero OL, Lo C, Lister R, Pelizzola M, et al. Global DNA hypomethylation coupled to repressive chromatin domain formation and gene silencing in breast cancer. Genome Res. 2012;22(2):246-58.

15. Esteve-Puig R, Bueno-Costa A, Esteller M. Writers, readers and erasers of RNA modifications in cancer. Cancer Lett. 2020. https://doi.org/10.1016/j. canlet.2020.01.021.

16. Li Z, Guo X, Wu Y, Li S, Yan J, Peng L, et al. Methylation profiling of 48 candidate genes in tumor and matched normal tissues from breast cancer patients. Breast Cancer Res Treat. 2015. https://doi.org/10.1007/ s10549-015-3276-8.

17. Feng W, Orlandi R, Zhao N, Carcangiu ML, Tagliabue E, Xu J, et al. Tumor suppressor genes are frequently methylated in lymph node metastases of breast cancers. BMC Cancer. 2010. https://doi.org/10.1186/ 1471-2407-10-378.

18. Umetani N, Mori T, Koyanagi K, Shinozaki M, Kim J, Giuliano AE, et al. Aberrant hypermethylation of ID4 gene promoter region increases risk of lymph node metastasis in T1 breast cancer. Oncogene. 2005;24(29):4721.
19. Benevolenskaya EV, Islam AB, Ahsan H, Kibriya MG, Jasmine F, Wolff $B$, et al. DNA methylation and hormone receptor status in breast cancer. Clin Epigenetics. 2016. https://doi.org/10.1186/s13148-016-0184-7.

20. Kloten V, Becker B, Winner K, Schrauder MG, Fasching PA, Anzeneder T, et al. Promoter hypermethylation of the tumor-suppressor genes ITIH5, DKK3, and RASSF1A as novel biomarkers for blood-based breast cancer screening. Breast Cancer Res. 2013;15(1):R4.

21. Cao X, Tang Q, Holland-Letz T, Gündert M, Cuk K, Schott S, et al. Evaluation of promoter methylation of RASSF1A and ATM in peripheral blood of breast cancer patients and healthy control individuals. Int J Mol Sci. 2018;19(3):900.

22. Coyle YM, Xie X-J, Lewis CM, Bu D, Milchgrub S, Euhus DM. Role of physical activity in modulating breast cancer risk as defined by APC and RASSF1A promoter hypermethylation in nonmalignant breast tissue. Cancer Epidemiol Biomarkers Prev. 2007;16(2):192-6.

23. Real SAS, Parveen F, Rehman AU, Khan MA, Deo SVS, Shukla NK, et al. Aberrant promoter methylation of YAP gene and its subsequent downregulation in Indian breast cancer patients. BMC Cancer. 2018;18(1):711.

24. Jin W, Li Q-Z, Zuo Y-C, Cao Y-N, Zhang L-Q, Hou R, et al. Relationship between DNA methylation in key region and the differential expressions of genes in human breast tumor tissue. DNA Cell Biol. 2019;38(1):49-62.

25. Bardou P, Mariette J, Escudié F, Djemiel C, Klopp C. jvenn: an interactive Venn diagram viewer. BMC Bioinformatics. 2014;15(1):293.

26. Sanchez-Vega F, Mina M, Armenia J, Chatila WK, Luna A, La KC, et al. Oncogenic signaling pathways in the cancer genome atlas. Cell. 2018;173(2):321-37.e10.

27. Wang Y, Xu X, Maglic D, Dill MT, Mojumdar K, Ng PK-S, et al. Comprehensive molecular characterization of the hippo signaling pathway in cancer. Cell Rep. 2018;25(5):1304-17.e5.

28. Olayioye MA, Neve RM, Lane HA, Hynes NE. The ErbB signaling network: receptor heterodimerization in development and cancer. EMBO J. 2000;19(13):3159-67.

29. Maric G, Annis MG, MacDonald PA, Russo C, Perkins D, Siwak DR, et al. GPNMB augments Wnt-1 mediated breast tumor initiation and growth by enhancing PI3K/AKT/mTOR pathway signaling and $\beta$-catenin activity. Oncogene. 2019;38:5294-307.

30. Vogelstein B, Kinzler KW. Cancer genes and the pathways they control. Nat Med. 2004;10(8):789-99.

31. Chen Y-C, Sosnoski DM, Mastro AM. Breast cancer metastasis to the bone: mechanisms of bone loss. Breast Cancer Res. 2010;12(6):215.

32. Akech J, Wixted JJ, Bedard K, Van der Deen M, Hussain S, Guise TA, et al. Runx2 association with progression of prostate cancer in patients: mechanisms mediating bone osteolysis and osteoblastic metastatic lesions. Oncogene. 2010;29(6):811-21.

33. Korkut A, Zaidi S, Kanchi RS, Rao S, Gough NR, Schultz A, et al. A PanCancer analysis reveals high-frequency genetic alterations in mediators of signaling by the TGF- $\beta$ superfamily. Cell Syst. 2018;7(4):422-37.e7.

34. Guise TA, Mundy GR. Cancer and bone. Endocr Rev. 1998;19(1):18-54.

35. Tate JG, Bamford S, Jubb HC, Sondka Z, Beare DM, Bindal N, et al. COSMIC: the catalogue of somatic mutations in cancer. Nucleic Acids Res. 2019;47(D1):D941-D7.

36. Abbott KL, Nyre ET, Abrahante J, Ho Y-Y, Isaksson Vogel R, Starr TK. The Candidate Cancer Gene Database: a database of cancer driver genes from forward genetic screens in mice. Nucleic Acids Res. 2015;43(D1):D844-D8.

37. Pletscher-Frankild S, Pallejà A, Tsafou K, Binder JX, Jensen LJ. DISEASES text mining and data integration of disease-gene associations. Methods. 2015;74:83-9.

38. Love MI, Huber W, Anders S. Moderated estimation of fold change and dispersion for RNA-seq data with DESeq2. Genome Biol. 2014;15(12):550.

39. Bibikova M, Barnes B, Tsan C, Ho V, Klotzle B, Le JM, et al. High density DNA methylation array with single $\mathrm{CpG}$ site resolution. Genomics. 2011;98(4):288-95.

40. Yang $X$, Gao L, Zhang S. Comparative pan-cancer DNA methylation analysis reveals cancer common and specific patterns. Brief Bioinform. 2017;18(5):761-73.

41. Weber M, Davies JJ, Wittig D, Oakeley EJ, Haase M, Lam WL, et al. Chromosome-wide and promoter-specific analyses identify sites of differential DNA methylation in normal and transformed human cells. Nat Genet. 2005;37(8):853-62. 
42. Pennacchio LA, Bickmore W, Dean A, Nobrega MA, Bejerano G. Enhancers: five essential questions. Nat Rev Genet. 2013;14(4):288-95.

43. Maston GA, Evans SK, Green MR. Transcriptional regulatory elements in the human genome. Annu Rev Genomics Hum Genet. 2006;7:29-59.

44. Bell RE, Golan T, Sheinboim D, Malcov H, Amar D, Salamon A, et al. Enhancer methylation dynamics contribute to cancer plasticity and patient mortality. Genome Res. 2016;26(5):601-11.

45. Zhou Y, Zhou B, Pache L, Chang M, Khodabakhshi AH, Tanaseichuk O, et al. Metascape provides a biologist-oriented resource for the analysis of systems-level datasets. Nat Commun. 2019;10(1):1523.

46. Györffy B, Lanczky A, Eklund AC, Denkert C, Budczies J, Li Q, et al. An online survival analysis tool to rapidly assess the effect of 22,277 genes on breast cancer prognosis using microarray data of 1,809 patients. Breast Cancer Res Treat. 2010;123(3):725-31.

\section{Publisher's Note}

Springer Nature remains neutral with regard to jurisdictional claims in published maps and institutional affiliations.

- fast, convenient online submission

- thorough peer review by experienced researchers in your field

- rapid publication on acceptance

- support for research data, including large and complex data types

- gold Open Access which fosters wider collaboration and increased citations

- maximum visibility for your research: over 100M website views per year

At BMC, research is always in progress.

Learn more biomedcentral.com/submissions 